Article

\title{
High-Stress Abrasion and Impact-Abrasion Testing of Wear Resistant Steels
}

\author{
Vilma Ratia $^{1)^{*}}$, Kati Valtonen ${ }^{1)}$, Anu Kemppainen ${ }^{2)}$ and Veli-Tapani Kuokkala ${ }^{1)}$ \\ ${ }^{1)}$ Tampere University of Technology, Department of Materials Science, Tampere Wear Center \\ P.O.Box 589, 33101 Tampere, Finland \\ ${ }^{2)}$ Ruukki Metals Inc. \\ P.O.Box 93, 92101 Raahe, Finland \\ *Corresponding author: vilma.ratia@tut.fi
}

( Manuscript received 10 March 2012; accepted 15 January 2013; published 15 February 2013 )

( Presented at Technical Session in the International Tribology Conference Hiroshima 2011)

\begin{abstract}
Energy can be saved by enhancing the service life of machinery and by designing lighter units. These design changes enable, for example, lower fuel consumption and larger payloads. The implementation of this kind of solutions, however, requires development of better wear resistant materials. In this study, the wear resistance of a structural steel and three grades of wear resistant steel was evaluated with granite abrasive in tests simulating the conditions in heavy machinery in mining and transportation. Two high-stress abrasion and one impact-abrasion wear testing methods were used. In all tests, higher hardness led to decreased mass loss, but in impact-abrasion the hardness dependence was smaller than in the heavy abrasion tests. This may, however, at least partly result from deformation of softer materials over the sample edges, which is not shown as mass loss. Wear surfaces of structural steel samples exhibited the highest degree of plastic deformation due to their lower hardness and higher ductility compared to the wear resistant steels. On the other hand, in harder materials the scratches were more visible, indicating a change in wear mechanism. Both differences and similarities in the behavior and wear mechanisms of the selected steels were observed in the applied conditions.
\end{abstract}

Keywords: abrasion, hardness, impact, steel, wear

\section{Introduction}

Severe conditions in earthmoving and mining cause heavy wear in equipment used in the field. For example, it has been estimated that $6350 \mathrm{~kg}$ of steel is used for replacements per excavation bucket in just six months [1]. In the development towards less energy consumption, besides reducing the use of materials, energy can be saved by enhancing the service life of machinery and by designing lighter units. Lighter units enable less fuel consumption and larger payloads. However, the implementation of these solutions requires the use of more durable materials.

The suitability of materials for a certain application can be assessed by field and laboratory testing. Laboratory testing enables controlled conditions and lower costs. In laboratory tests, however, the testing conditions need to be simplified in order to create a well controlled system. Wear testing is often conducted by using industrial abrasives of a narrow size distribution for better control of the abrasive properties. On the other hand, to simulate the real conditions properly, also testing with natural abrasives is important.

In applications such as earthmoving and mining machinery, the gravel and minerals generate heavy abrasion and impact wear. Moreover, the material can be subjected to several different kinds of conditions during its service. Loading, unloading and transportation all cause slightly different conditions to the tipper body, as the movement of the abrasive relative to the material surface and the applied load vary. Thus, more than one type of testing with various conditions and parameters is needed to assess the wear properties of the materials. In this work, the wear of selected steel grades was studied using natural granite as an abrasive in three different test procedures to simulate the severe conditions in these kinds of applications. Two high-stress abrasion and one high-stress impact-abrasion methods were used.

One of the classifications of abrasive wear is the division into high-stress abrasion and low-stress abrasion. In high-stress abrasion, the stress in the wear area is sufficient to cause crushing of the abrasive. In low-stress 
abrasion, the abrasives remain intact. [2] In all testing methods used in this study, crushing of the abrasives occurs. Thus, based on this classification, they all are high-stress abrasion testing methods.

In earlier studies [3-5], similar impact-abrasion wear testing equipment has been used in addition to, for example, dry sand rubber wheel or pin-on-disc testing. However, the particle size used in the latter mentioned abrasive testing methods has been typically much smaller than the one used in impact-abrasion testing, i.e., 40-300 $\mu \mathrm{m}$ compared to $1.6-25 \mathrm{~mm}$.

Rendón and Olsson [3] compared the results of impeller-tumbler and pin-on-disc with abrasive paper. 12-20 mm quartzite gravel was used in the impeller-tumbler tests and $\mathrm{SiC}$ paper of mesh 320 in the pin-on-disc tests. The authors observed clear differences in the resulting wear surfaces and formed tribolayers under the surface: the impeller-tumbler produced a thicker tribolayer with embedded abrasives whereas the samples tested with the pin-on-disc did not have any embedded abrasives. However, in those tests, the abrasive for testing the impact-abrasive and the abrasive wear was not similar and the difference in the grain size was substantial. Moreover, the abrasives in the abrasive wear method were fixed to a paper, causing mainly two-body abrasive wear. Considering mining and transportation applications, the abrasive material is usually loose.

The low and high impact loading impeller-tumbler tests of four hardfacing alloys were compared to standard ASTM G65 rubber wheel test and single impact test results by Badisch et al. [4]. They used 212-300 $\mu \mathrm{m}$ Ottawa silica sand for the ASTM G65 tests and 1.6-2.2 $\mathrm{mm}$ silica sand or 5-10 mm corundum for the low and high impact loading tests in impeller-tumbler, respectively. It was found that the performance of the materials in those tests strongly depended on the microstructure. However, although impact, impact-abrasive and abrasive conditions were covered in the testing, the abrasive was different in all methods and thus the significant difference in abrasive properties also had an effect on the results.

Tylczak et al. [5] tested several steel types in the field and in multiple laboratory tests. They used pin-on-drum testing with approximately $100 \mu \mathrm{m}$ garnet as the abrasive,
ASTM G65 rubber wheel testing with 200-300 $\mu \mathrm{m}$ rounded silica, jaw crusher test with $25.4 \mathrm{~mm}$ quartzite, and impeller-tumbler with 19-25 mm quartzite. Increased hardness reduced the wear of the materials with a linear correlation in the abrasive pin-on-drum and ASTM G65 tests. However, the gouging abrasion in jaw crusher and impact-abrasion in impeller-tumbler caused different wear behavior and the correlation between hardness and wear resistance was negligible. This extensive study with several testing methods produced variable wear environments, but there was a notable difference between the used abrasive sizes.

In real-life applications, the used abrasive media causes both impacts and abrasion. Thus, it is important to use comparable abrasives when testing several wear modes with different tests. In the present study, the abrasive was natural stone granite in all testing methods. The particle sizes in the abrasive and impact-abrasive tests were on average $5-6 \mathrm{~mm}$ and $11 \mathrm{~mm}$, respectively, so they were close to each other. To correlate to the real life applications, the testing methods were selected to simulate the steps of a transportation process: loading, transportation and unloading. The impact-abrasive impeller-tumbler method simulates loading, where the gravel falls onto the tipper body with abrasion resistant steel plates. Crushing abrasion by the uniaxial crusher method simulates the compaction and transportation of the heavy loads. The unloading, where the load slides on the floor plates of the tipper body, is simulated by the crushing pin-on-disc, in which the samples are subjected to heavy abrasive conditions between a pin and a rotating disc. The study aims to present differences and similarities in the behavior and wear mechanisms of the selected steel grades in versatile heavy abrasion conditions, which are typical for earth moving and mining processes. The results assist the material selection in these applications.

\section{Experimental methods}

This Chapter presents the tested steels and the abrasive. In addition, the used wear testing methods are introduced together with the analyzing equipment used to determine the mass losses and to characterize the wear surfaces after the tests.

Table 1 Surface hardness and typical mechanical properties of the test materials

\begin{tabular}{|c|c|c|c|c|c|}
\hline \multirow[b]{2}{*}{ Material } & \multicolumn{3}{|c|}{ Hardness [HB] } & \multirow[b]{2}{*}{$\begin{array}{l}\text { Tensile strength } \\
R_{m}\left[\mathbf{N} / \mathbf{m m}^{2}\right]\end{array}$} & \multirow[b]{2}{*}{$\begin{array}{l}\text { Elongation } \\
\text { A5 [\%] }\end{array}$} \\
\hline & $\begin{array}{l}\text { Crushing } \\
\text { pin-on-disc }\end{array}$ & $\begin{array}{l}\text { Uniaxial } \\
\text { crusher }\end{array}$ & $\begin{array}{l}\text { Impeller- } \\
\text { tumbler }\end{array}$ & & \\
\hline S355 & 162 & 162 & 154 & $430-530$ & 24 \\
\hline Raex 400 & 368 & 368 & 403 & 1250 & 10 \\
\hline Raex 450 & - & 445 & 456 & 1450 & 8 \\
\hline Raex 500 & 492 & 469 & 492 & 1600 & 8 \\
\hline
\end{tabular}


Table 2 Parameters of the applied testing methods

\begin{tabular}{|c|c|c|c|c|}
\hline Method & Wear type & Motion & Force & $\begin{array}{l}\text { Abrasive } \\
\text { size }\end{array}$ \\
\hline $\begin{array}{l}\text { Crushing } \\
\text { pin-on-disc }\end{array}$ & $\begin{array}{l}\text { High-stress } \\
\text { abrasion }\end{array}$ & $\begin{array}{l}\text { crushing } \\
\text { sliding }\end{array}$ & $200 \mathrm{~N}$ & $2-10 \mathrm{~mm}$ \\
\hline Uniaxial crusher & $\begin{array}{l}\text { High-stress } \\
\text { abrasion }\end{array}$ & crushing & $53 \mathrm{kN}$ & $4-6.3 \mathrm{~mm}$ \\
\hline Impeller-tumbler & $\begin{array}{l}\text { High-stress } \\
\text { impact-abrasion }\end{array}$ & $\begin{array}{l}\text { impact } \\
\text { sliding }\end{array}$ & N/A & $\begin{array}{l}10-12.5 \\
\mathrm{~mm}\end{array}$ \\
\hline
\end{tabular}

\subsection{Materials}

The materials studied in this work were a structural steel (S355) and three martensitic wear resistant steels (Raex) manufactured by Ruukki Metals, Inc. Table 1 presents the Brinell hardness values and typical tensile strengths and elongation values of the test materials. The hardness of the same steel grades used in different tests varied, because they were from different batches.

Granite was the abrasive used in all tests, but its size distribution varied slightly with the test method. To minimize the effect of natural variation in the properties of the rock material, the abrasives were all from a single batch from Sorila quarry in Finland. Table 2 presents the size distributions used for different testing methods. The abrasive size distributions were chosen to cause the most severe wear conditions within the limits of the testing devices. The abrasive was crushed and angular in shape.

\subsection{Methods}

The materials were tested using two high-stress abrasive and one high-stress impact-abrasive wear testing method. The equipment was designed and constructed at the Tampere Wear Center. The differences between the methods are the motion of the sample

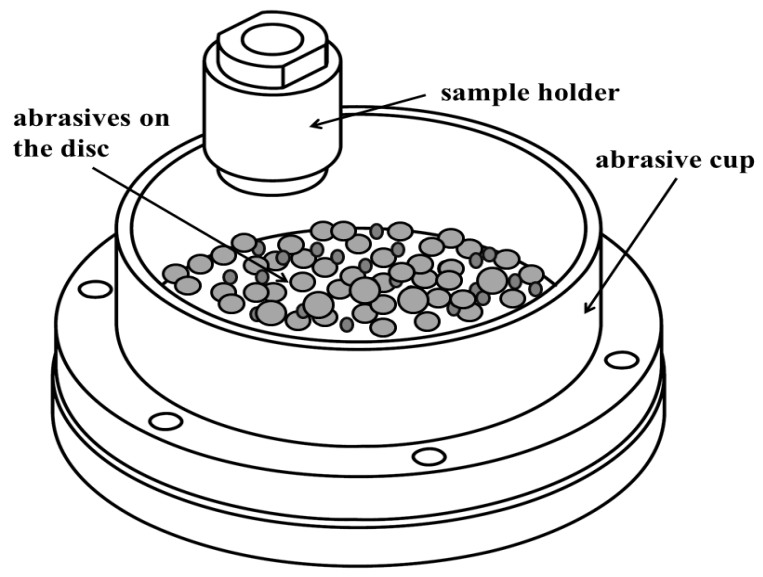

Fig. 1 Crushing pin-on-disc wear test device surface and the applied force. In the crushing pin-on-disc method, the sample is subjected to both crushing and sliding, whereas in the uniaxial crushing method the motion is uniaxial and there is no sliding movement between the sample and the counterpart. In the current tests, the applied force was substantially higher in the uniaxial crusher, approximately 265 times that in the crushing pin-on-disc. In the impeller-tumbler method, the sample is subjected to both impacts and sliding of loose abrasives. Table 2 presents the characteristic parameters of each testing method. All tests were conducted at room temperature.

\subsubsection{Crushing pin-on-disc}

The crushing pin-on-disc test method [6], which is based on the common pin-on-disc principle, was used to determine the abrasion wear resistance of the test materials. In the crushing pin-on-disc method, loose abrasive is placed between the rotating disc and the pin, which is cyclically pressed against the abrasive. Figure 1 illustrates the crushing pin-on-disc device. The pin and the disc are not in direct contact at any point of the test.

In the current tests, the pin sample was a solid cylinder with a diameter of $36 \mathrm{~mm}$, creating a wear area of $1000 \mathrm{~mm}^{2}$. The orientation of the sample pin was not fixed and thus it could rotate around its own axis to cause even wear throughout the sample surface. The diameter of the disc was $160 \mathrm{~mm}$. The used discs were structural steel for the S355 and wear resistant steel for Raex samples. Table 3 presents the hardness of the used discs. The rotating speed of the disc was $28 \mathrm{rpm}$ and the sliding distance of the pin center point during the test

Table 3 Hardness of the discs used in crushing pin-on-disc

\begin{tabular}{|c|c|}
\hline Disc & Hardness [HB] \\
\hline S355 & 205 \\
\hline Raex 400 & 461 \\
\hline Raex 500 & 520 \\
\hline
\end{tabular}


Table 4 The abrasive size distribution used in the crushing pin-on-disc testing method

\begin{tabular}{|c|c|}
\hline Size distribution $[\mathbf{m m}]$ & Mass $[\mathbf{g}]$ \\
\hline $2-4$ & 50 \\
\hline $4-6.3$ & 250 \\
\hline $6.3-8$ & 150 \\
\hline $8-10$ & 50 \\
\hline$\Sigma$ & 500 \\
\hline
\end{tabular}

approximately $120 \mathrm{~m}$. The force used in the current tests was $200 \mathrm{~N}$.

Table 4 presents the size distribution of the abrasive mixture used in the tests. This distribution causes efficient wear in the samples in this testing method. The total amount of gravel in one test was $500 \mathrm{~g}$. The abrasive in the cup was not changed during the test, which led to changing testing conditions due to comminution of the abrasive by crushing. However, the abrasive in the pin-rock interface was replenished between each crush by cyclically lifting the pin above the gravel bed. The pin was cyclically pressed down for $5 \mathrm{~s}$ and then lifted up for $2.5 \mathrm{~s}$ for the abrasive to change in the pin-rock interface due to the rotation of the disc. The duration of the test was 30 minutes, which equals approximately 240 compressions and 20 minutes of contact time. To reach the steady-state wear, the samples were subjected to a 20 minute running-in stage before the actual test. The standard deviation of the results obtained with the crushing pin-on-disc method is on average $7 \%$.

\subsubsection{Uniaxial crusher}

The uniaxial crusher method [7] was used to evaluate the durability of the test materials under plain compression by the abrasive media. Figure 2 presents the crushing section of the uniaxial crusher device. In the present study, the gravel was crushed between the sample and the tool steel counterpart with hardness of $690 \mathrm{HV}$ in a rubber cup. The movement of the sample is vertical, so the sample and the counterpart do not move in relation to each other. For every compression, the gravel is replaced using an automatic supply tube that fills the cup. A rotary actuator tilts the cup to empty it from the crushed abrasive at the end of each cycle. The used abrasive was granite of the size distribution $4-6.3 \mathrm{~mm}$. This size enabled steady removal and replacement of the abrasive.

The samples were similar to those used in the crushing pin-on-disc tests, having a wear surface of 1000 $\mathrm{mm}^{2}$. The used force was $53 \mathrm{kN}$. The running-in stage included 100 compressions, and the duration of the actual test was 900 compressions. The standard deviation of the results with this method is approximately $15 \%$.

\subsubsection{Impeller-tumbler}

The impeller-tumbler wear tester was used to measure the impact-abrasion wear resistance of the test

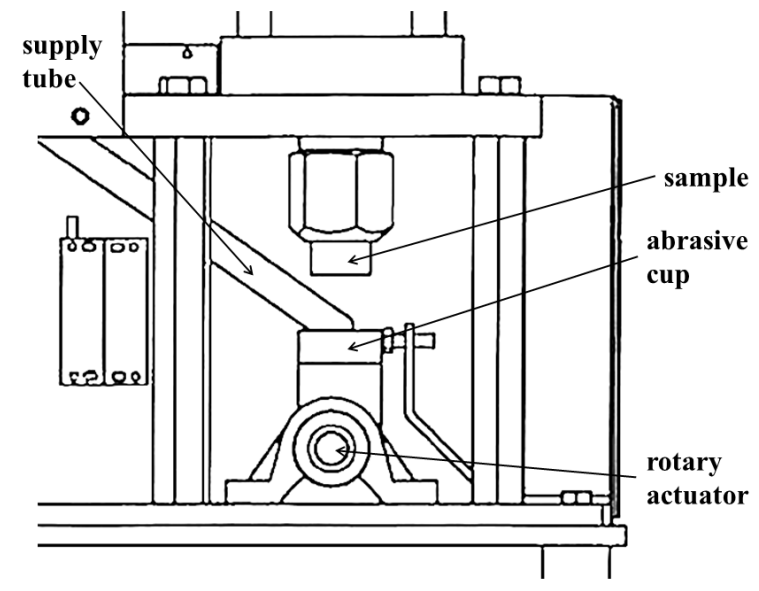

Fig. 2 Crushing section of the uniaxial crusher device

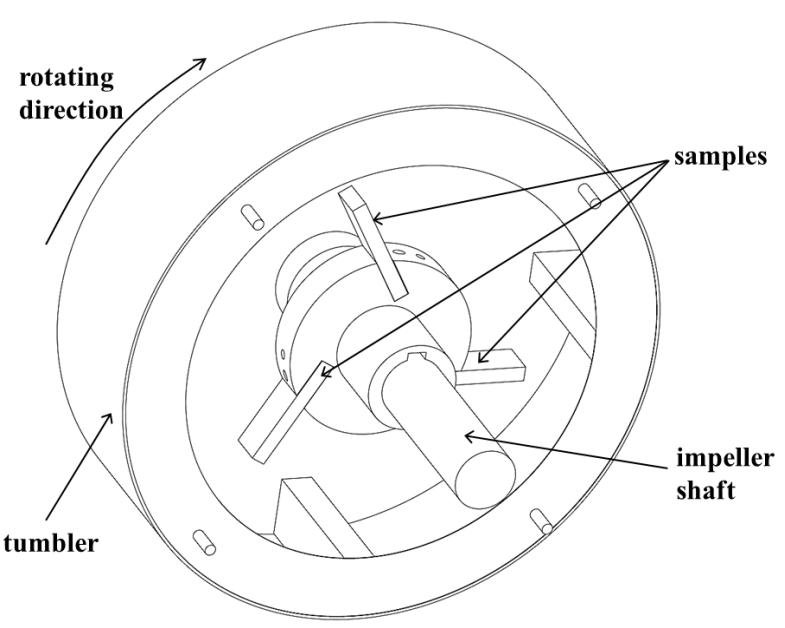

Fig. 3 Impeller-tumbler wear test device

materials. Figure 3 presents a schematic picture of the impeller-tumbler device. The samples act as impeller blades attached to the sample holder, and the tumbler contains the gravel. Both the impeller and the tumbler rotate in the same direction at rotation speeds of $700 \mathrm{rpm}$ and $30 \mathrm{rpm}$, respectively. During the test, the samples are impacted and scratched by the moving abrasives, which are kept in motion with the tumbler. The diameter of the tumbler is $350 \mathrm{~mm}$.

In the present tests, the sample size was $75 \times 25 \times 5$ $\mathrm{mm}$, of which $1200 \mathrm{~mm}^{2}$ constituted the wear surface. The distance from the outer edge of the sample to the center of the sample holder was approximately $105 \mathrm{~mm}$. The samples were attached at a $60^{\circ}$ angle to the sample holder perimeter. It must, however, be emphasized that the sample angle in this method is not equal to the abrasive incidence angle, as the abrasive particles are loose and move freely inside the tumbler and thus impact the samples at arbitrary angles.

The duration of each test was 60 minutes. The 
samples were weighted and the abrasive was renewed every 15 minutes. The running-in stage was 15 minutes. Three samples were tested simultaneously, one of which was always a Raex 400 reference sample. This enabled accounting for the effects of property variance of the natural abrasives. The samples were circulated in the sample holder slots to exclude the possible effects of the sample positions. The reference sample was kept in the same slot for the whole test to provide steady conditions for it. The mass losses were calculated as an average of the result from three samples in relation to the mass loss of the reference sample. The standard deviation of the results was less than $3 \%$.

The used abrasive was granite of $10-12.5 \mathrm{~mm}$ in size. Larger particle size correlates with higher wear rates, which is why a larger abrasive size was used with the impeller-tumbler than with the other methods. The amount of gravel in the tumbler was $900 \mathrm{~g}$. As the abrasive was renewed every 15 minutes, the total amount of abrasive in a 60 minute test was $3600 \mathrm{~g}$. The particle count was approximately 410 in each $900 \mathrm{~g}$ gravel batch.

\subsubsection{Analyzing methods}

The wear rate was determined by measuring the mass loss during the test. The samples were cleaned with pressurized air or ethanol before weighting. The accuracy of the used balance was $0.001 \mathrm{~g}$.

Veeco Wyko NT1100 optical profilometer was used for surface roughness measurements. The measurements were conducted with $5 \mathrm{x}$ objective and 0.5 field of view lens. The results were filtered using the median 3 filter.

The Vickers hardness HV0.1 of the worn samples was measured with Matsuzawa MMT-X7 microhardness tester from the cross sections as close to the surface as possible to reveal the possible work hardening of the material. The penetration depth in the wear scars was determined from the cross-sections with Leica DM 2500 M optical microscope. The cross sections from the length of $5 \mathrm{~mm}$ were studied and the maximum depth of each distinguishable scar inside the $5 \mathrm{~mm}$ region was

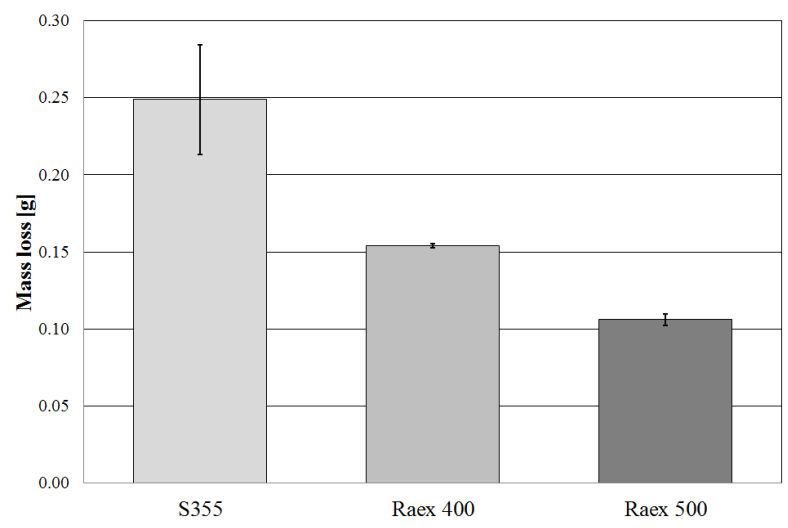

Fig. 4 Crushing pin-on-disc wear test results. The error bars indicate standard deviation measured.

The wear surfaces were characterized with Leica MZ 7.5 zoom stereomicroscope and Philips XL30 scanning electron microscope (SEM). The samples were cleaned in ultrasonic bath and sputtered with a thin layer of gold to avoid charging of the abrasive remnants on the surface.

\section{Results}

In this Chapter, the wear test results and their correlation to the mechanical properties are presented. Moreover, the characterization of wear surfaces by surface roughness, penetration depth and hardness measurements are presented along with observations made by optical and electron microscopy.

\subsection{Wear tests}

The wear rate of the samples was determined by mass loss measurements. The effect of the abrasive remnants on the mass loss measurements was minimized by doing a running-in phase to all samples. In this way, the steady state of wear was reached before starting the actual test.

\subsubsection{Crushing pin-on-disc}

Figure 4 presents the mass loss results for the pins in the crushing pin-on-disc tests. The mass loss of S355 was much higher than that of the wear resistant steels. The difference between the wear resistant steels was evident as well, the mass loss of Raex 500 being approximately $30 \%$ lower than the mass loss of Raex 400.

\subsubsection{Uniaxial crusher}

Figure 5 presents the mass loss results from the uniaxial crusher tests. The mass loss of S355 was more than double compared to the wear resistant steels. On the other hand, the wear resistant steels showed smaller differences between each other than in the crushing pin-on-disc test.

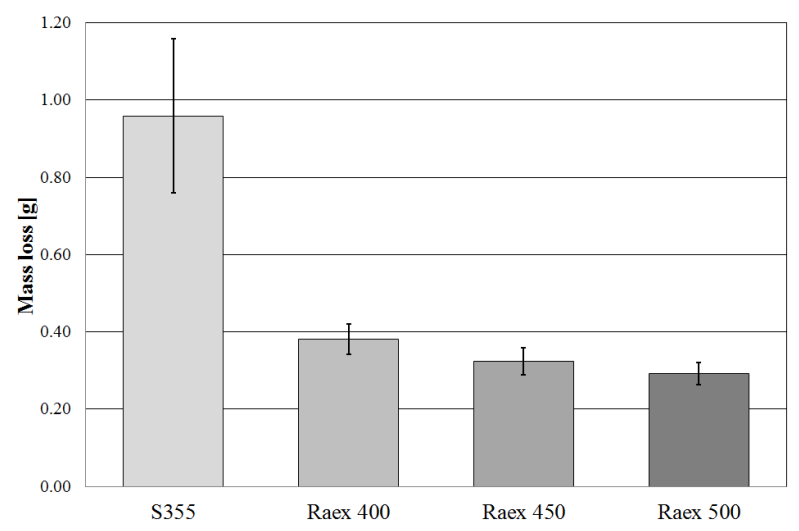

Fig. 5 Uniaxial crusher wear test results. The error bars indicate standard deviation 


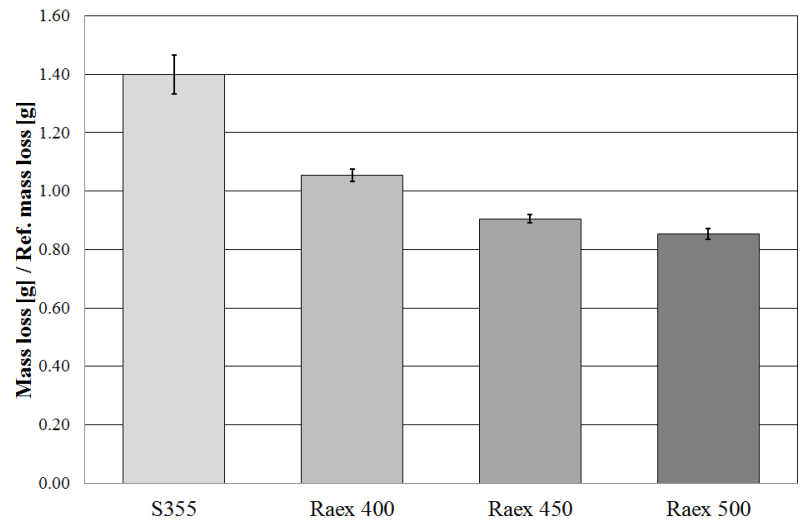

Fig. 6 Impeller-tumbler wear test results. The error bars indicate standard deviation

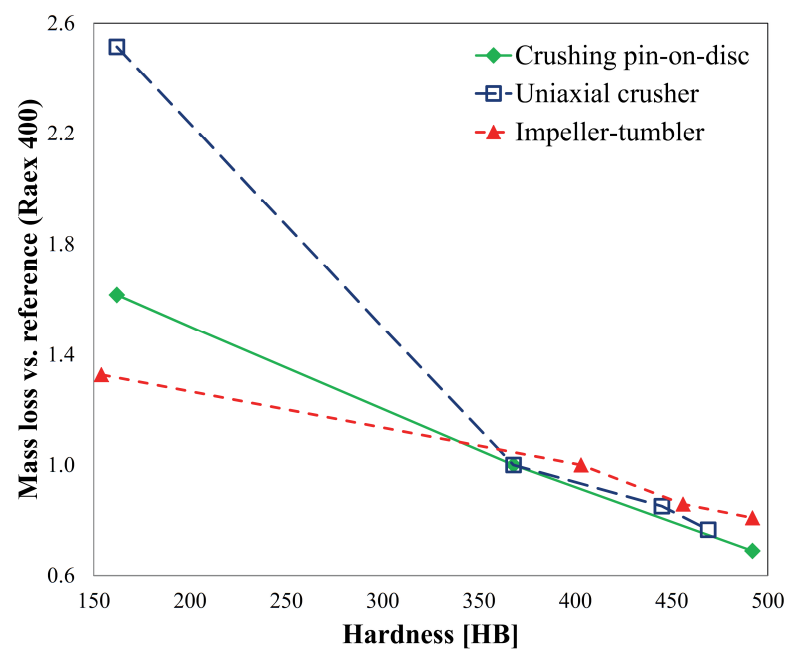

Fig. 7 Results of the wear tests as mass loss vs. material hardness. The mass losses have been normalized by the mass loss of the reference material

\subsubsection{Impeller-tumbler}

The results of the impeller-tumbler wear tests are presented in Figure 6. The results reveal that the difference between the wear resistant steels and the structural steel is substantially smaller than with other methods used in this study. The difference within the wear resistant steels is similar to that in the uniaxial crusher results.

\subsection{Role of mechanical properties}

A summary of the wear test results for all test methods in correlation with hardness is presented in Figure 7 . To be able to compare the results obtained by different methods and conditions, the results were scaled by the wear rate of the reference material. The used reference material was Raex 400, as it gave reasonably constant results and was thus well suited for a reference material.

In all tests, higher hardness led to lower wear rate, but the strength of this relationship varied. The crushing

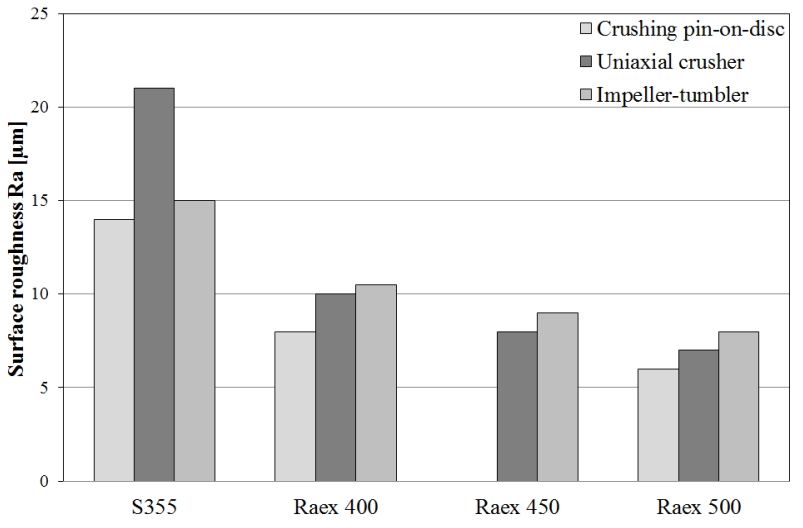

Fig. 8 Ra values for wear tested samples $[\mu \mathrm{m}]$

pin-on-disc and impeller-tumbler tests produced quite linear curves. For impeller-tumbler results, the correlation of the higher hardness with the reduction of wear was lower than for the other methods. In the uniaxial crusher tests, the difference in the wear rates between the structural steel and wear resistant steels was large. However, in this method the dependence of wear on hardness for the wear resistant steels was much weaker.

The correlation between the wear test results and the ultimate tensile strength was very similar to the correlation between the hardness and wear, which was expected as the tensile strength and hardness usually show a quite linear correspondence. In all methods, higher ultimate tensile strength decreased wear. In impact-abrasion with impeller-tumbler, the dependence was weaker than in the abrasive methods.

Considering the typical elongation or ductility values, higher ductility correlated with higher mass loss results. Again, the strength of the dependence varied with test conditions, abrasive methods producing a stronger correlation than the impact-abrasion method.

\subsection{Hardness of the worn surface}

The results indicated that work hardening takes place to some extent in all studied steels, but the effect is much smaller in harder steels. In the structural steel, the hardness increased substantially in samples tested with all methods. The increase of hardness in the region down to $50 \mu \mathrm{m}$ from the surface was 100-160 HV. In wear resistant steels the hardening could not be observed as clearly. In Raex 400, the hardness increased approximately 30-50 HV in the corresponding region. In harder Raex 500, the increase was even smaller. There was no distinct difference observed between the methods.

\subsection{Surface roughness measurements}

The surface roughness was determined with an optical profilometer. The initial surface roughness of the samples was approximately $0.5 \mu \mathrm{m}$. Figure 8 presents the results as an average of five measurements for each 
sample. Materials with lower hardness showed in general higher surface roughness values after the tests. In the abrasion tests, the difference between the structural and wear resistant steels was significantly larger than in the impact-abrasion tests. In the high-stress abrasion tests, the surface roughness of the S355 samples was at least $70 \%$ higher than that of the wear resistant steels.

\subsection{Penetration depths}

The deepest individual scars were observed in uniaxial crusher samples, where the deepest scars found in the studied regions were $133 \mu \mathrm{m}$ for S355 and $71 \mu \mathrm{m}$ for Raex 500. The uniaxial crusher produced the deepest scars also on average, whereas the crushing pin-on-disc produced the shallowest scars on average. However, the scatter of the measurements was large, as every wear scar is different and therefore the average penetration depth value can be heavily influenced by a few deeper wear scars. When comparing materials, the harder materials had smaller penetration depths both on average and defined by the deepest individual scars within the studied regions.

\subsection{Wear surface studies}

The wear surfaces of tested samples were characterized using a stereomicroscope and a scanning electron microscope. The stereomicroscope enabled the observation of larger surface formations, while with SEM it was possible to study the wear surfaces in detail. The abrasive remnants were easily distinguished from the steel with a backscatter electron detector (BSE). To provide quantitative information about the amount of abrasive remnants, energy dispersive X-ray spectrometry (EDS) was used.

\subsubsection{Crushing pin-on-disc}

Both two-body and three-body abrasive wear occurred in all steel samples, and scratches and rolling marks were present on all surfaces. Figure 9 presents a SEM image of a S355 sample with a clear scratch mark on an otherwise evenly deformed wear surface. In the

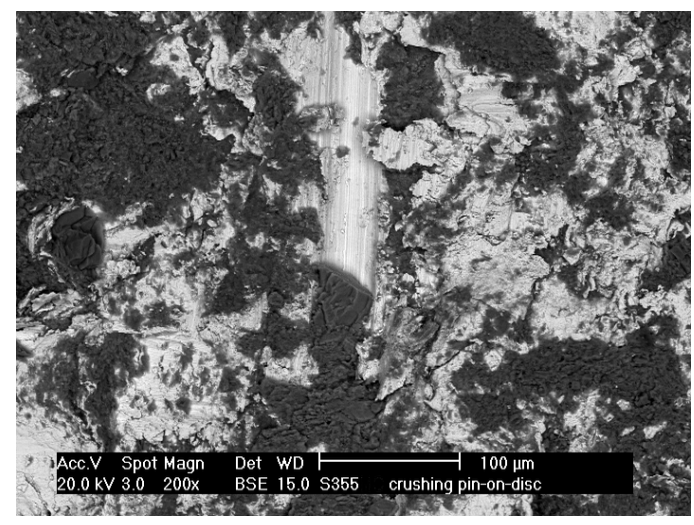

Fig. 9 SEM image of a wear surface of S355 tested with the crushing pin-on-disc (BSE mode)
BSE image, the lighter areas are metal and abrasive remnants are shown as dark.

Signs of both ploughing and cutting were detected on all studied surfaces. The degree of plastic deformation was much higher in the structural steel than in the wear resistant steels, and also the amount of embedded abrasives was much larger. The structural steel had some large burrs on the surface, whereas in the wear resistant steels the formations were more chip-like, smaller and edgier, obviously due to the lower ductility of the material. Signs of severed chips were more visible in harder steels.

The surfaces of wear resistant steels were clearly flatter, as indicated also by the surface roughness measurements. Figure 10 presents shallow scratches on the wear surface of Raex 500. The scratches were more visible in steels with higher hardness. When determining the number of scratches from stereo optical images, the number of detectable scratches was approximately twice as high in Raex 500 as in S355.

\subsubsection{Uniaxial crusher}

The wear surfaces of the samples tested with the uniaxial crusher revealed indentations, plastic

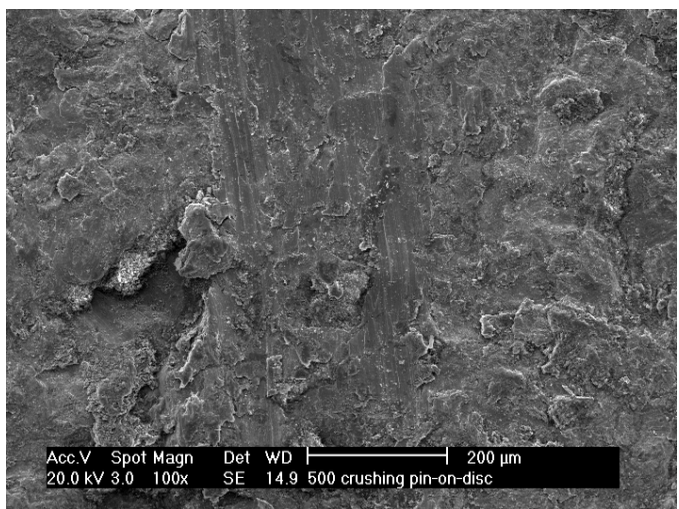

Fig. 10 SEM image of a wear surface of Raex 500 tested with the crushing pin-on-disc

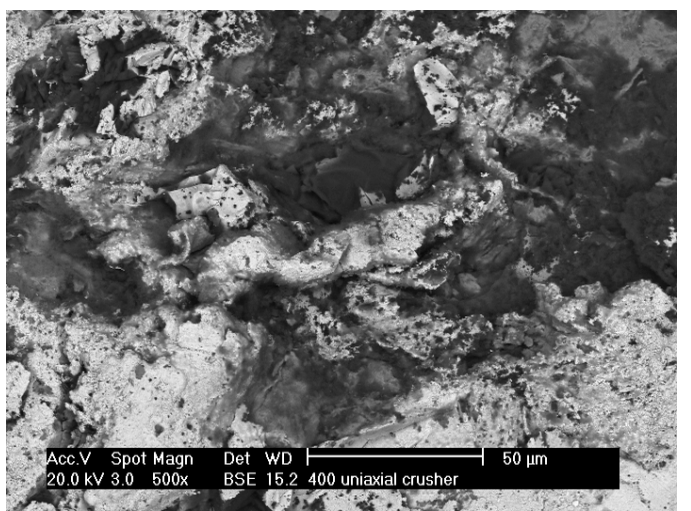

Fig. 11 SEM image of a wear surface of Raex 400 tested with the uniaxial crusher (BSE mode) 


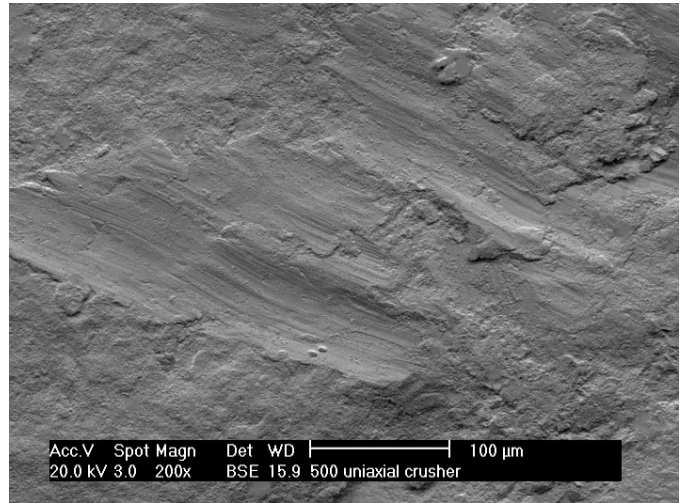

Fig. 12 SEM image of a wear surface of Raex 500 tested with the uniaxial crusher (topographic BSE mode)

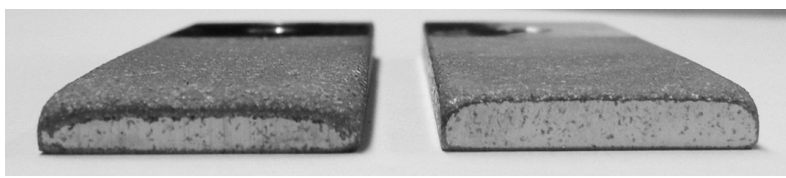

Fig. 13 Impeller-tumbler sample edges of S355 (on the left) and Raex 400 (on the right)

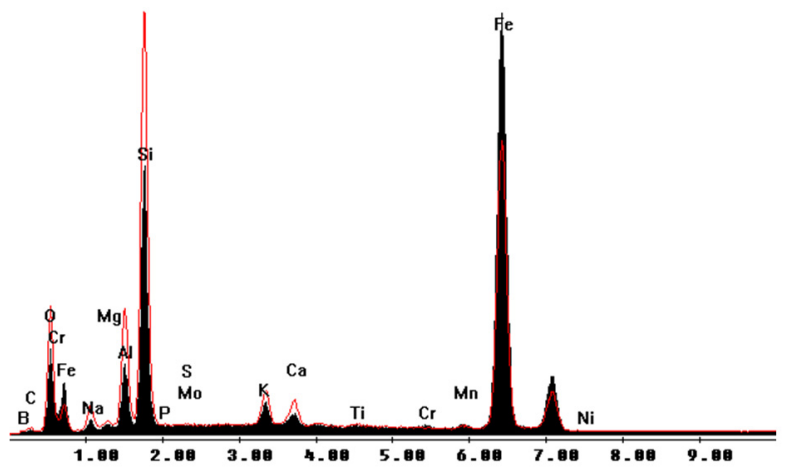

Fig. 14 Comparative EDS spectra from worn surfaces of S355 (red line) and Raex 500 (black graph)

deformation and microscratches. As the rocks in the abrasive bed were crushed, they moved relative to each other and could slide for short distances on the surface of the sample. The structural steel contained more abrasive remnants than the wear resistant steels, but embedded abrasive could be found in all samples. Figure 11 shows dark abrasive remnants on the lighter metal surface of worn Raex 400.

Similarly to the crushing pin-on-disc tests, the structural steel was severely deformed while the harder materials exhibited flatter and smoother surfaces. On the other hand, there were more well-defined short scratches in the harder materials. Figure 12 presents a SEM image of scratches on the surface of Raex 500.

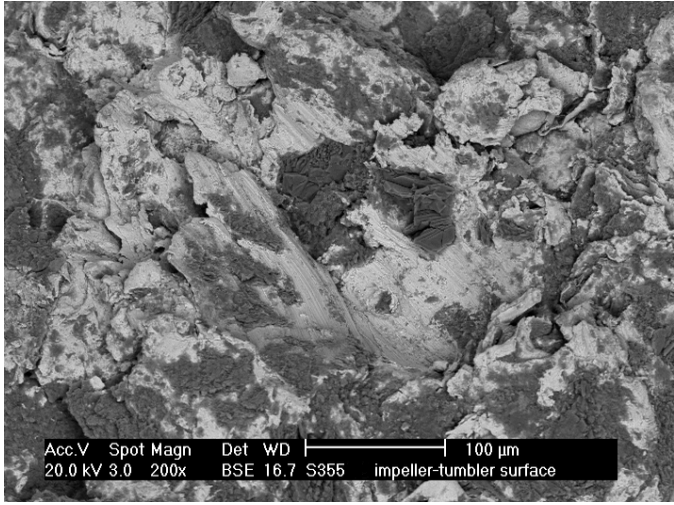

Fig. 15 SEM image of a wear surface of S355 tested with the impeller-tumbler (BSE mode)

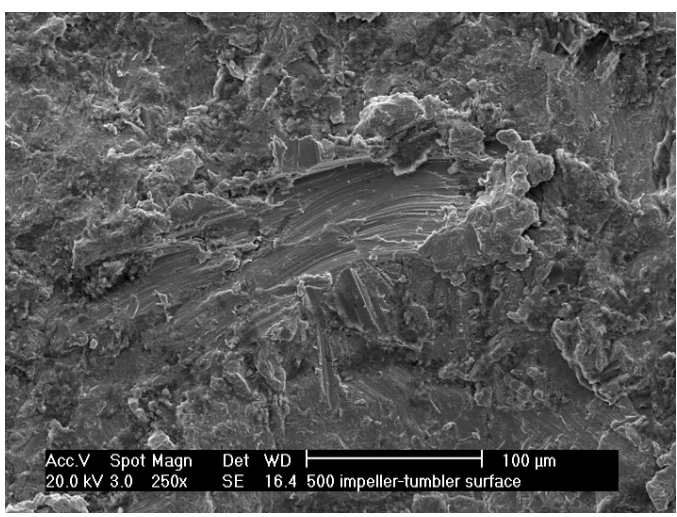

Fig. 16 SEM image of a wear surface of Raex 500 tested with the impeller-tumbler

\subsubsection{Impeller-tumbler}

In the samples tested with the impeller-tumbler, wear was most severe in the sample edges. Figure 13 shows the edges of the structural steel and Raex 400 samples. In both samples the edges are clearly rounded, but in the structural steel the rounding is much heavier and the material has been displaced over the sample's edge as a burr. In the wear resistant steel only slight burring was observed.

When studying the wear surfaces in the center areas of the samples, the structural steel contained more abrasive remnants compared to the wear resistant steels. Figure 14 presents EDS spectra from both S355 and Raex 500 impeller-tumbler wear surfaces. Compared to Raex 500, the analysis from the S355 surface contains considerably more silicon, aluminum and potassium, which are the major elements in granite [8]. This also indicates a larger amount of embedded rock on the S355 surface.

Figure 15 presents a heavily deformed wear surface of S355 with extensive ploughing, wedges and chips. In the wear resistant steels, the chips and wedges were smaller and the degree of deformation was lower. It 
seemed that besides scratching, wear has occurred largely by the removal of the formerly deformed areas through the following impacts.

Figure 16 presents a scratch on the wear surface of Raex 500. In general the scratches were more well-defined and the surfaces smoother in the harder materials. When determining the number of scratches from the stereo optical images, the number of detectable scratches was approximately twice as high in Raex 500 as in S355.

\section{Discussion}

In agreement with the common observation, also in the current tests higher hardness correlated with better wear resistance, but the degree of this relation varied with the applied wear conditions. In general, a harder material resists the penetration of the abrasive through its higher surface hardness and strength, decreasing the wear rate. For samples tested in the impact-abrasion conditions (i.e., the impeller-tumbler tests), the positive effect of hardness was substantially smaller than for the high-stress abrasion methods. Also Rendón et al. [3] and Hawk et al. [9] have reported that in the impeller-tumbler tests the change in the wear rate can be notably small even for relatively large changes in the alloy hardness.

The results of this study, however, could at least partly be connected to edge-concentrated wear. The sample edges were not shielded in any of the applied test types, but in the impeller-tumbler samples the wear of the edges was clearly most severe. One explanation for the relatively low wear rate (as quantified by the mass loss) of the structural steel in the impeller-tumbler tests is the higher ductility that enables the material to deform around the edges by forming a burr without actual removal of the material. In the wear resistant steels only very small burrs could be observed, which suggests that the removal of the material in the edges occurs mostly by cutting and cracking of the deformed edges.

In order to enable the comparison of the abrasion wear resistance of materials in the center areas of the sample, i.e., to exclude the edge effects, the tests should be conducted with shielded edges. Especially in the impeller-tumbler tests, wear at the sample edges possibly dominates the measured mass losses. However, the wear of the edges correlates well with the real wear conditions in the tipper body, where the edge part of the tail plate is subjected to most severe wear.

There were some similarities in the wear surfaces produced by all testing methods. All the studied wear surfaces were plastically deformed and contained abrasive remnants on the surface. The structural steel was always the most heavily deformed and contained most abrasive remnants. On the other hand, the most distinct scratches were found in the harder steels in all methods.

However, the differences in the wear conditions and their effects on the steels' behavior could be easily detected also on the wear surfaces. In the structural steel samples, wear was most severe in samples tested with the uniaxial crusher, where the relative mass loss, surface roughness and penetration depth values were clearly the highest of all samples. This is a direct result of the much higher forces applied in this test method.

In the impeller-tumbler test, the nature of the contact between the abrasive and the sample is more of an impact than in the other test methods. Sundström et al. [10] have determined the ratio of impact and abrasion to be 100/1 in a similar type test equipment. In the structural steel the material can be more easily deformed and displaced than removed due to its higher ductility compared to wear resistant steels, in which the material seems to be more easily cut away from the surface by impacts. This decreases the effect of hardness on the wear rate.

The crushing pin-on-disc is a three-body abrasion test method, and thus the effect of the counterpart cannot be excluded. Axén et al. [11] stated that the amount of rolling increases as the hardness of the counterpart material increases. In their study, self-mated steel surfaces in three-body abrasion showed about equal amounts of rolling and sliding. In the tests of the present study, the counterpart was slightly harder than the sample, possibly promoting rolling of abrasives on the pin sample. Differences in the behavior of the pin materials could be observed. Based on wear surface examination, the amount of scratching increased as the material hardness increased. Both the surface roughness and penetration depth were the smallest for Raex 500 in this method, suggesting that even when the amount of scratches was higher, they were only shallow and thus did not cause substantial material removal. The similarity of the hardness of the Raex 500 pin and the disc, and thus the higher pin/disc hardness ratio compared to the other tested materials, may have promoted sliding on the Raex 500 pin surface in this method. However, higher amount of scratches was observed also in the Raex 400 pin.

For all methods, harder materials contained more scratches. This was basically for two reasons: in these materials less deformation occurs to cover the previous scratches, and the proportion of sliding is higher than in softer materials. The increased sliding results from the ability of the harder material to resist the penetration of the abrasives. For an angular abrasive to roll, some deformation, either elastic or plastic, must occur in the surface. The harder surface resists this more, thus increasing the propensity to sliding instead of rolling. Gore and Gates [12] reported that increased specimen hardness led to a transition from rolling to sliding of the abrasive particles in three-body abrasive wear, which agrees with the wear scars found in this study. Also Fang et al. [13] observed more scratches in harder materials in their study concentrating on abrasive wear in materials with a wide range of hardness. For impeller-tumbler, a same kind of observation about the scratches, although less defined, was done by Sundström et al. [10]. 


\section{Conlusions}

For all materials and test methods used in this study, higher hardness led to decreased mass loss. The strength of this dependence, however, varied depending on the test method and other properties of the materials. Impact-abrasion showed the weakest dependence on hardness, possibly due to the concentration of wear by cutting on the specimen edges. In this case, the higher ductility of the structural steel enabled the material to deform and create burrs over the sample edges without actual loss of material.

In all testing methods, the degree of plastic deformation was the highest in the structural steel, which was the softest material. On the other hand, in harder materials the scratches were more well-defined and visible, indicating a change in the wear mechanism. For an angular abrasive to roll, some kind of deformation must occur in the surface. The harder surface resists this more, increasing the possibility of sliding. The lower degree of plastic deformation was also not sufficient to cover the formed scratches as effectively as in the softer materials.

This study shows that the performance of different steels depends on the conditions of abrasive wear. The used test methods complement each other and provide useful laboratory scale simulations of the wear conditions typical in earth moving and mining.

\section{Acknowledgements}

The work has been done within FIMECC Ltd and its DEMAPP program. We gratefully acknowledge the financial support from Tekes and the participating companies.

\section{References}

[1] Hawk, J. A. and Wilson, R. D., "Tribology of Earthmoving, Mining, and Minerals Processing," in Modern Tribology Handbook, Vol. 2, Bhushan, B. (ed.), CRC Press, Boca Raton, 2000.

[2] Zum Gahr, K.-H. (ed.), "Grooving Wear," in Tribology Series, Vol. 10, Elsevier, Amsterdam, 1987, p. 132.

[3] Rendón, J. and Olsson, M., “Abrasive Wear Resistance of Some Commercial Abrasion
Resistant Steels Evaluated by Laboratory Test Methods," Wear, 267, 11, 2009, 2055-2061.

[4] Badisch, E., Kirchgaßner, M., Polak, R. and Franek, F., "The Comparison of Wear Properties of Different Fe-Based Hardfacing Alloys in Four Kinds of Testing Methods," Tribotest, 14, 4, 2008, 225-233.

[5] Tylczak, J. H., Hawk, J. A. and Wilson, R. D., “A Comparison of Laboratory Abrasion and Field Wear Results," Wear, 225-229, 2, 1999, 1059-1069.

[6] Terva, J., Teeri, T., Kuokkala, V.-T., Siitonen, P. and Liimatainen, J., "Abrasive Wear of Steel against Gravel with Different Rock-Steel Combinations," Wear, 267, 11, 2009, 1821-1831.

[7] Heino, V., Kaipiainen, M., Siitonen, P., Ratia, V., Valtonen, K., Lepistö, T and Kuokkala, V-T., "Compressive Crushing of Granite with Wear-Resistant Materials," Finnish Journal of Tribology, 30, 1-2, 2011, 21-28.

[8] Silva, B. and Aira, N., Martínez-Cortizas, A., Prieto, B., "Chemical Composition and Origion of Black Patinas on Granite," Science of the Total Environment, 408, 1, 2009, 130-137.

[9] Hawk, J. A., Wilson, R. D., Tylczak, J. H. and Doğan, Ö. N., "Laboratory Abrasive Wear Tests: Investigation of Test Methods and Alloy Correlation," Wear, 225-229, 2, 1999, 1031-1042.

[10] Sundström, A., Rendón, J. and Olsson, M., "Wear Behaviour of Some Low Alloyed Steels under Combined Impact/Abrasion Contact Conditions," Wear, 250, 1-12, 2001, 744-754.

[11] Axén, N., Jacobson, S. and Hogmark, S., "Influence of Hardness of the Counterbody in Three-Body Abrasive Wear - An Overlooked Hardness Effect," Tribology International, 27, 4, 1994, 233-241.

[12] Gore, G. J. and Gates, J. D., "Effect of Hardness on Three Very Different Forms of Wear," Wear, 203-204, 1997, 544-563.

[13] Fang, L., Zhou, Q. D. and Li, Y. J., "An Explanation of the Relation between Wear and Material Hardness in Three-Body Abrasion," Wear, 151, 2, 1991, 313-321. 